\title{
Intelligent Automatic Traffic Challan on Highways and Payment Through FASTag Card
}

\author{
Abhishek Sontakke*, Aman Diwakar and Gaganjot Kaur \\ Department of Computer Science Engineering, Manav Rachna University, Sector 43, Faridabad, \\ Haryana 121004, India; Abhisheksontakke92@gmail.com, amandiwakar110@gmail.com, gaganjot@mru.edu.in
}

\begin{abstract}
Background/objectives: With the advent of Internet of Things (IoT), Government has taken a huge step in the field of Trafficking to initiate a hassle free and most convenient way such as using Radio Frequency Identification (RFID) cards to pay at the Toll Plaza. Methods/statistical analysis: The Indian Government in association with the National Highway Authority of India (NHAI), understood the pain and introduced electronic toll collection (ETC), christened it as "FASTag". So, India's highways are going cashless with FASTag and vehicles do not need to stop at toll plaza for the cash transactions. Findings: This study deals with the application of the latest technology of the FASTag which is beneficial in avoiding the traffic hassle at the National toll plazas. With the use of FASTag installed on the front windshield of vehicles, toll generation is made a fun job. Automatically, the toll charges are deducted from FASTag account. This technology can also be used for the generation of challan and automatic deduction through the FASTag linked to the vehicle. Improvements/applications: The major applications of this aspect are Automatic Challan generation on the national highways which includes OverSpeeding, Seat Belt, Wrong-way driving, Parking in "No Parking" Zone, driving without a Valid Permit, and Overtaking from the Wrong Side.
\end{abstract}

Keywords: FASTag, RFID, Electronic Toll Collection, ETC, National Highway Authority of India, NHAI

\section{Introduction}

The National Highway Authority of India (NHAI) has come up with an innovative approach of collection of tolls through FASTag, which is an electronic toll collection system being implemented at more than $350+$ toll plazas across India. A separate FASTag lane has been provided by the NHAI on the toll plazas which indicates the approaching vehicles having FASTag installed correctly to pass hassle-free and smoothly without any stopping. A large banner displaying "FASTag Lane" makes the drivers more cautious about it. If any vehicle does not have proper installed FASTag system and deliberately passes through the toll will be charged double as fine. $\underline{1}$

FASTag is associated with the Radio Frequency Identification (RFID) affixed to the windshield of the vehicle for automatic verification and deduction of tolls on the National Highways directly from the Bank Account linked to the FASTag. The vehicles can pass through the gateway without any stoppage and avoid any sort of time delay. $\underline{\underline{2}}$ This is due to the mechanism between RFID Scanner present underneath the FASTag banner and the RFID attached on the vehicle. The scanner reads the RFID on the vehicle and verifies it, makes deductions from the account of the driver, and the process continues. $\underline{3}$

The Issuer Agency deducts the relevant toll fee from the customer's prepaid account linked to the FASTag and this whole process is computerised. This reasoning will be done post the toll exchange. The customers enjoying the benefits of FASTag need to maintain their funds in their account linked to the FASTag. It will be called as a Top-up. This paper proposed a novel framework of effective pricing of Toll rates.

${ }^{*}$ Author for correspondence 


\subsection{Background}

\subsubsection{RFID}

RFID functions with the help of electromagnetic fields to intelligently scan and track tags attached to the devices. The information is stored electronically inside these tags. The passive tags collect energy from a nearby RFID reader through radio waves, whereas the active tags are embedded with the local power source and can function from hundreds of meters away from RFID scanner. RFID is a technology which provides Automatic Identification and Data Capture (AIDC). The government has introduced an effective way by affixing RFID tags on the vehicle and using it as a toll plaza wallet. This tag is known as FASTag. $\underline{4}-\underline{7}$

FASTag is a tag, which is affixed on the vehicle's windshield. It utilises Radio-Frequency Identification (RFID) technology, which further uses electromagnetic fields to automatically verify and track the FASTag attached to the vehicle's windshield. $\underline{5}$ The FASTag sticker has a hidden chip that stores the owner's information electronically. Due to this, the scanners at the FASTag Toll lanes can easily read the data and the toll amount are deducted whenever the vehicle approaches the Toll Plaza lanes. It is linked and verified by a prepaid account of the owner of the vehicle having FASTag system installed and the toll amount is deducted from their prepaid accounts.

FASTag is the best solution for a fast and traffic-free trip on National Highways especially at the Toll Plazas. At present, it is functional at $350+$ toll plazas across different states and national highways. With the greater need of technology, according to the demands of the future, the day is not far when everybody will be using FASTag system as the common source of toll transactions across the globe $\underline{\underline{6}-\underline{8}}$ as shown in Figures 1 and 2. Various banks and payment merchants have partnered with NHAI for FASTag transactions. The only necessity is to link FASTag to one of these banks for toll deductions. Once the ID number is linked to this account, all the applicable tolls are deducted automatically from this account.

Following are the key benefits of utilizing RFID-based FASTag:

- Cashless transactions: with the benefit of the cashless transaction, hassle is reduced at the toll plaza.

- Online recharge: Online recharges can be done using Paytm and various online transaction methods. It can be easily updated anytime and anywhere.

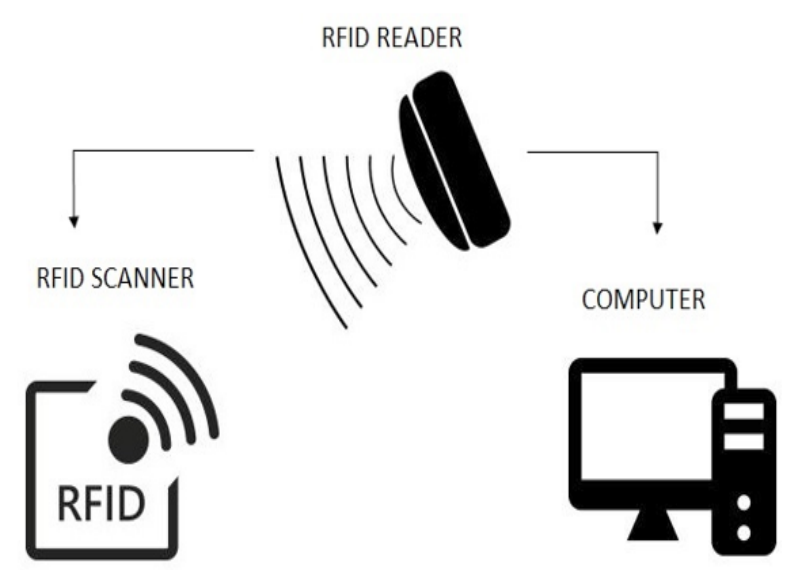

Figure 1. Working of RFID.

- Saves fuel and time: Automatic deduction at toll plaza is done effectively when the vehicle approaches the toll plaza.

- No paper wastage: SMS and Email are sent for transactions done are the tag.

- Online transaction: Provides a secure gateway which is transparent to the user. Improved transparency as all transactions completed through online.

- Balance alerts: Alerts are sent to the registered mobile number notifying about transaction details and low balance.

Following are the limitations of RFID-based FASTag technology:

- Some are the various limitations present in this hassle free FASTag-based technique:

- Technical errors: Sometimes due to some of the technical issues, the toll payer is made to wait for a certain period, these results in piling up the queue and finally results in more traffic jams on the toll plaza.

- Signal strength: Due to the visibility or damage of RFID, it can lead to lowering the signal strength and problem for the RFID receiver to verify the user and let him go.

- Health issues: Non-ionizing radiation might have biological effects that could result in cancer genic diseases.

- Minimum balance: There is a need to maintain minimum balance in the FASTag.

- Multiple entries: Not very useful for people, who do return through the same toll using the multiple entry pass. 


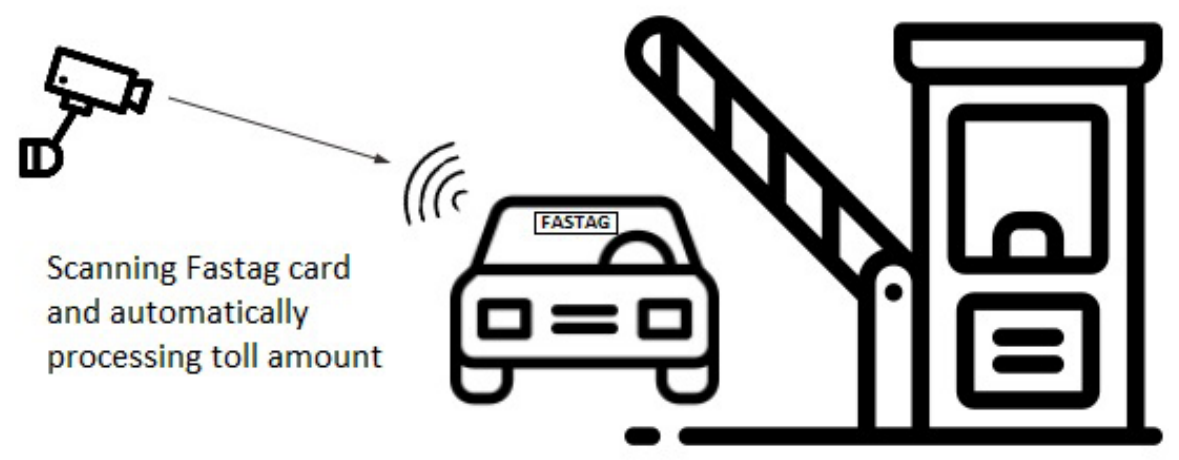

Figure 2. Working of FASTag.

Figure 3. Detecting car speed and Number Plate of Over speeding cars through NPR camera
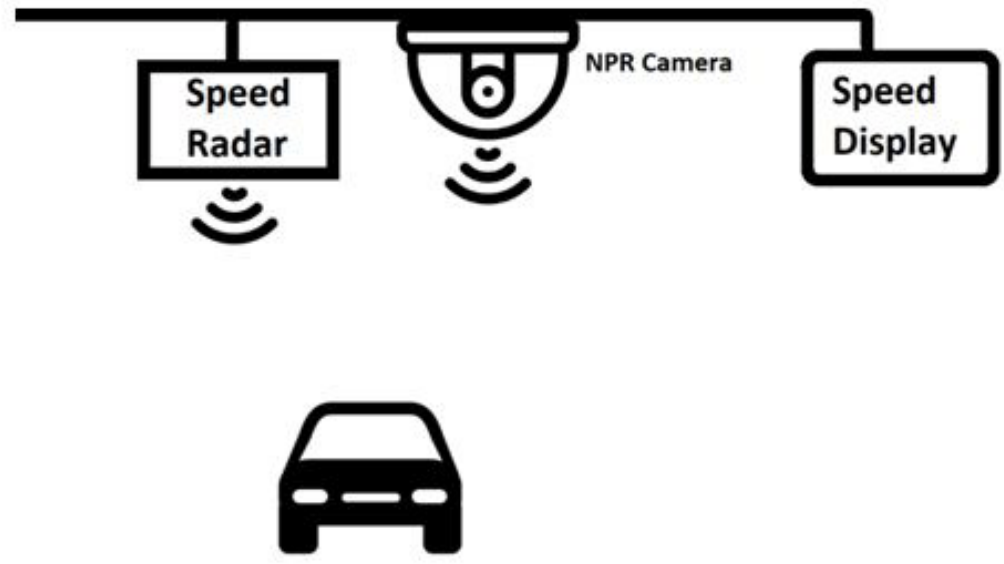

Figure 3. Detecting car speed and number plate of over speeding cars through NPR camera.

\section{Materials and Methods}

These days, there are too much traffic violations, taking lots of lives on the roads. Looking at the concern of large trafficking at the toll plaza and the number of deaths, we would like to track the people who are violating these rules and are not being caught by traffic police so that they can be charged money as punishment. People usually do rash driving at the highways and meet with accidents and pay their lives. According to the figures released by the government, more than 140,000 people died due to road accident in 2017. They also stated that nearly $80 \%$ accidents were caused by drivers, with $62 \%$ of those blamed for speeding.

\subsection{Criteria for Challan Generation on the National Highways}

\subsubsection{Over-Speeding}

On highways Speed Radars and number plate recognition (NPR) Cameras are present to capture the speed of vehicle and if the speed crosses the limit then NPR camera captures the number plate of the car. A message is sent to the mobile number registered with the registration certificate of that car indicating that he/she has exceeded the speed limit at location with the time stamp. Accordingly, a challan fee will be added to the FASTag and will be deducted as the car passes through the next FASTag lane at the National Toll Plaza as shown in Figures 3 and 4. 


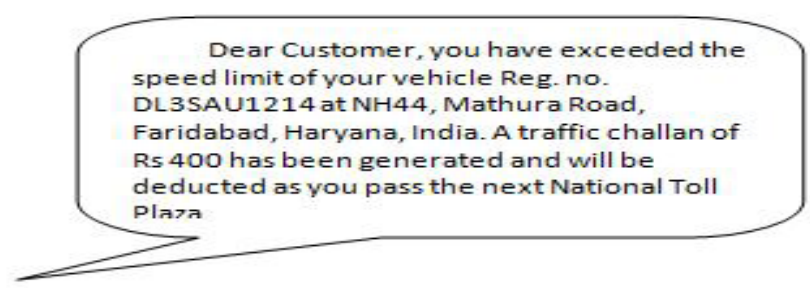

Figure 4. Challan message sent to mobile.

\subsubsection{No Seat Belt}

Driving without fastening seat belt results is caught by the surveillance camera placed on the toll both which costs in fine and a challan message is delivered to the mobile number registered with the registration certificate of that vehicle as shown in Figure 5.

\subsubsection{Wrong-way Driving}

Driving on the wrong side of the road is considered a traffic violation under section 184 of the Motor Vehicles Act. For the first offence, an offender may be booked for a six-month prison term or fined Rs 1000 . On the second instance, the period of imprisonment is increased to two years or/and the fine amount increases to Rs. 2000.

\subsubsection{Parking in "No Parking" Zone}

If a vehicle is parked under the no parking zone, then a traffic challan is generated according to the 15 (2) RRR 177 Motor Vehicle Act as shown in Figure 6.

\subsubsection{Driving Without a Valid Permit}

For commercial vehicles, valid permit is checked by the details fetched from the FASTag if validity fails penalty up to INR 5000 and no less than INR 2000 is charged under 130 r/w 177 Motor Vehicle Act.

\subsubsection{Overtaking from the Wrong Side}

If a vehicle overtakes from wrong side challan of is generated according to the 177 Motor Vehicle Act.

\subsection{Refund for Travelling Less Distance on Toll Road}

The current rules and regulations followed by the NHAI and the toll amount at the toll plazas is expensive if we talk about the distance travelled between two toll plazas
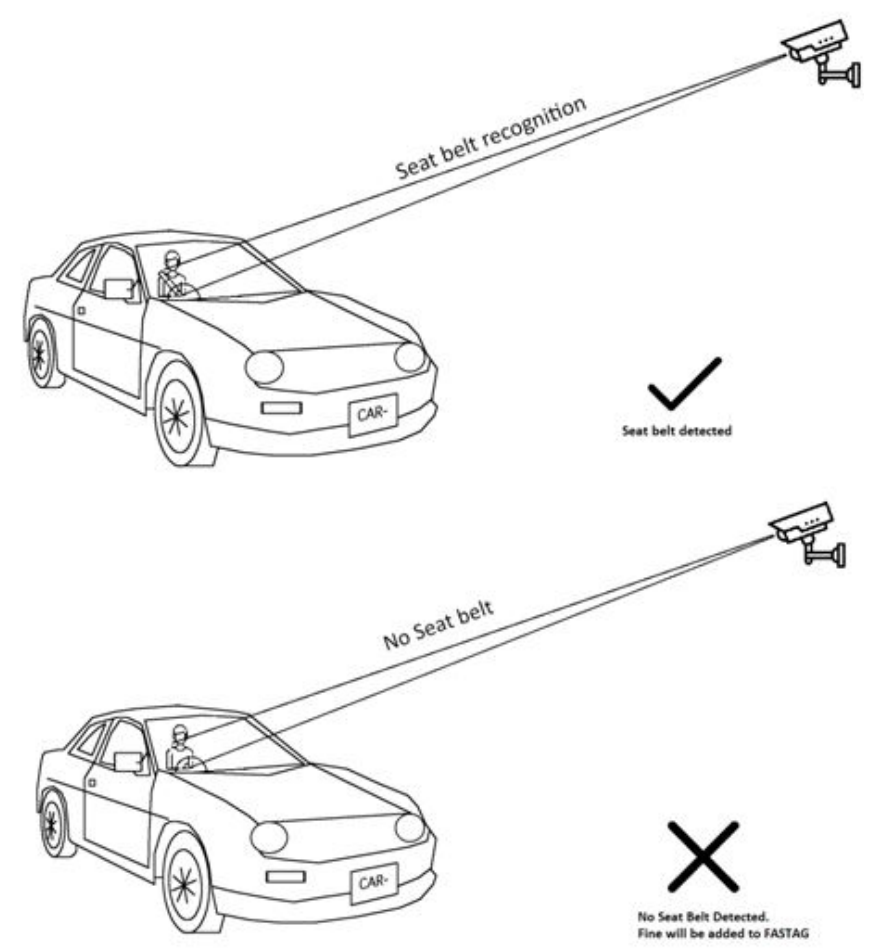

Figure 5. Detecting seat belt.

in two different cities. So, to avoid the loss to the users, we can charge the users for the distance they travelled after check-in at the toll plaza i.e., Charge for per kilometer as shown in Figure 7.

Car 1 and car 2 passes a toll plaza and pays same amount, suppose Rs 100. This toll has been given for the full toll road. As shown in the figure, car 1 passes the next toll plaza and travels $\mathrm{Y} \mathrm{km}$ whereas car 2 returns after travelling $\mathrm{X} \mathrm{km}$ but has paid the amount for full toll road. That means he is paying more than the usage. So, for providing benefit to the customer, a refund should be made. The deduction is according to the distance travelled on the toll road as shown in Table 1.

\subsection{Check-in Again Within $24 \mathrm{~h}$ in the Range of Toll Plaza, Let the Vehicle Go Without Payment of Toll}

Tracking location of the car and monitoring it for next $24 \mathrm{~h}$. If the vehicle passes the toll plaza first at 4:00 pm and if it come back before 4:00 pm on the next day in the range of toll plaza but while standing in the queue the time exceeds 4:00 pm then also toll charge will not be made. If it is deducted, refund will be processed within 24 $\mathrm{h}$ to FASTag card. The zone of toll plaza will be decided by 


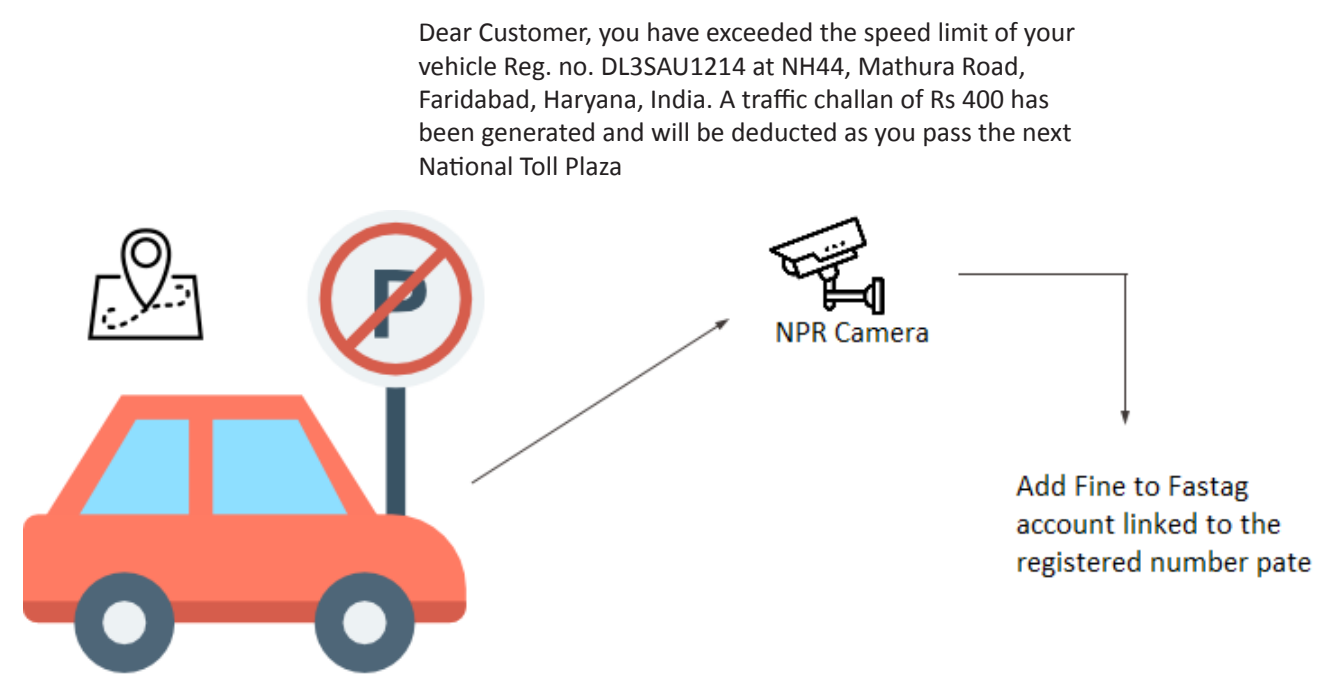

Figure 6. Detecting car parking in "No Parking" zone and generating challan.

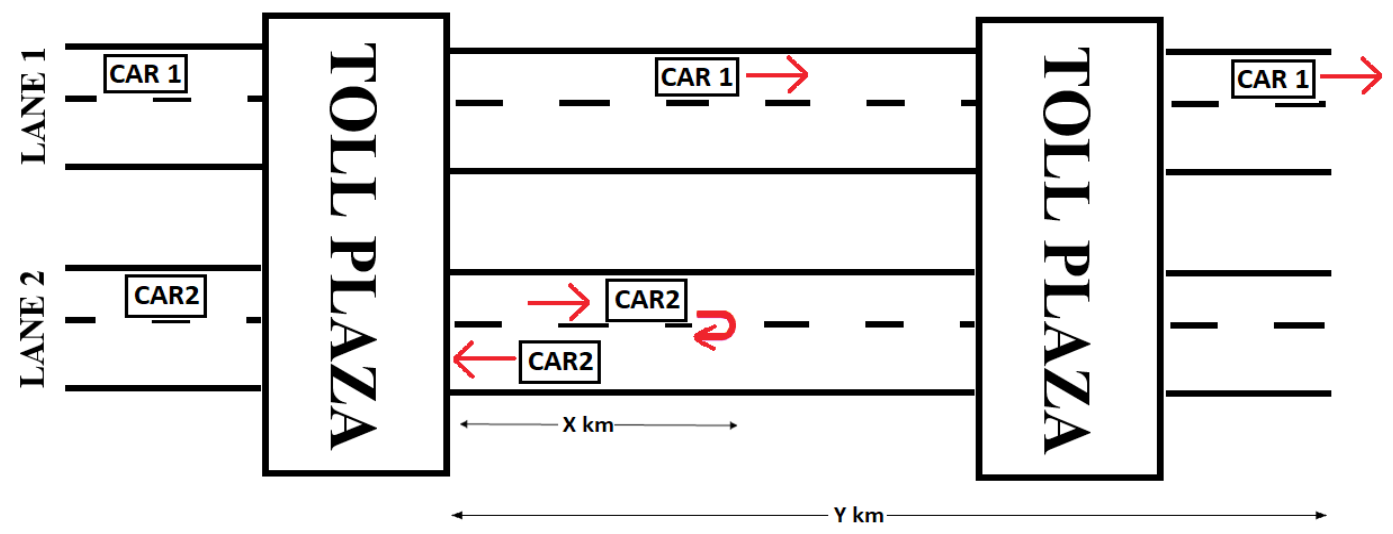

Figure 7. Toll road.

Table 1. Refund according to the distance travelled

\begin{tabular}{|l|c|}
\hline Distance range $\mathbf{( k m )}$ & Refund (\%) \\
\hline $0-10$ & $80 \%$ \\
\hline $10-20$ & $70 \%$ \\
\hline $20-30$ & $60 \%$ \\
\hline $30-40$ & $50 \%$ \\
\hline $40-50$ & $40 \%$ \\
\hline $50-60$ & $30 \%$ \\
\hline $60-70$ & $20 \%$ \\
\hline $70-80$ & $10 \%$ \\
\hline $80-100$ & $0 \%$ \\
\hline
\end{tabular}

adding a RFID reader about 500-1000 $\mathrm{m}$ before the toll plaza and detecting the vehicle so that the person is free by not paying the toll again.

\section{Results and Discussion}

This study deals with the application of the latest technology of the FASTag which is beneficial in avoiding the traffic hassle at the National toll plazas. Using the proposed method, FASTag automatically deducted the toll charges from the designated FASTag account. This proposed methodology can also be used for the generation of challan and automatic deduction through the FASTag linked to the vehicle, irrespective of the light motor vehicle and heavy motor vehicle. 


\section{Conclusion}

This study deals with the application of the latest technology of the FASTag which is beneficial in avoiding the traffic hassle at the National toll plazas. With the use of FASTag installed on the front windshield of vehicles, toll generation is made a fun job. Automatically, the toll charges are deducted from FASTag account. This technology can also be used for the generation of challan and automatic deduction through the FASTag linked to the vehicle. A solution for many people has been given who is suffering from being late by 1-2 min due to long queue at the toll plaza and paying the toll again.

\section{Acknowledgement}

We would like to express our thanks of gratitude to Accendere Knowledge Management Services for providing us a platform and opportunity to pursue the research.

\section{References}

1. Omarhommadil, Hussain Asiri, Mamdoohalzahrani. Comparison of different toll collections system's and RFID tool collection system. Am J Eng Res. 2017;6(1):118-21.
2. Electronic toll management system. http://pib.nic.in/ newsite/PrintRelease. aspx? relid $=154486$.

3. Giri P, Jain P. Automated toll collection system using RFID technology. Int J Adv Res Sci Eng. 2013;9(2):1-6.

4. FASTag is now active in over $70 \%$ toll plazas on national highway. [cited 2016 Apr 21]. https://thelogicalindian. com/news/fastag-is-now-active-in-over-70-toll-plazas-onnational-highways/.

5. Finkenzeller K. RFID Handbook: fundamentals and applications in contactless smart card identification. 2nd ed. John Wiley \& Sons; 2003.

6. Chin LP, Wu CL. The role of electronic container seal (E-seal) with RFID technology in the container security initiatives. In: Proceedings of the 2004 international conference on MEMS. NANO and Smart Systems; 2004. P. 116-20.

7. ISO/EC 18000-7. Information technology - radio frequency identification (RFID) for item management - part 7: parameters for active air interface communications at 433MHz; 2004.

8. India road crashes kill 146,133 people. [cited 2016 Jun 10]. https://www.bbc.com/news/world-asia-india-36496375. 